\title{
ANALISIS DAN PEMODELAN SISTEM PENGELOLAAN SAMPAH YANG ADA DI UNIVERSITAS MA CHUNG
}

\author{
Freta Natalia Salendu ${ }^{1)}$, Yuswono Hadi ${ }^{2)}$ \\ ${ }^{1)}$ Teknik Industri Universitas Ma Chung \\ ${ }^{2)}$ Teknik Industri Universitas Ma Chung \\ email : freta.natalia@gmail.com ${ }^{1)}$,yuswono.hadi@machung.ac.id ${ }^{2)}$
}

\begin{abstract}
Abstraksi
Aktivitas manusia dalam memenuhi kebutuhan tidak bisa dihindari dengan selalu menghasilkan sampah. Timbunan sampah yang terus menerus akan menyebabkan jejak karbon. Salah satu penyumbang timbunan sampah adalah aktivitas akademik. Universitas Ma Chung merupakan salah satu lembaga pendidikan di kota Malang. Universitas Ma Chung belum menjadi salah satu eco campus di Indonesia. Hal tersebut dapat diketahui dari pengelolaan sampah yang ada di Universitas Ma Chung. Oleh sebab itu diusulkan beberapa skenario yang dapat mengurangi jumlah sampah. Melakukan perhitungan menggunakan Stella untuk simulasi peningkatan jumlah sampah yang dihasilkan menggunakan metode Sistem Dinamis. Hasil perhitungan menunjukkan bahwa skenario usulan mengenai adanya air siap minum, untuk memenuhi kebutuhan air mineral sivitas akademik menurunkan jumlah sampah sekitar $945 \mathrm{~kg}$ untuk satu tahun ke depan dari kondisi awal. Hal tersebut menunjukkan bahwa skenario pertama sangat optimal karena dapat memenuhi kebutuhan konsumsi air mineral sivitas akademik yakni dengan menyediakan air siap minum di Universitas Ma Chung.
\end{abstract}

Kata Kunci:

Sistem Dinamis, Pemodelan Sistem, Pengelolaan Sampah, Solusi Optimal.

\begin{abstract}
Human activities in fulfiling their needs cannot be separated with the resulted wastes. More piles of waste will remain the carbon track. However, one of contributors the pile of wastes is academic activities. Ma Chung University is one of educational institutions in Malang. Ma Chung University has not become one of eco campus in Indonesia. It can be found out from the waste management in Ma Chung University. Therefore, some scenarios have been proposed in order to minimize the amount of wastes. In this research, the researcher calculated them using Stella for simulation of the increasing wastes. Result of the calculation showed that the proposal scenario about potable water in order to fulfill the need for mineral water, the academicians should reduce the wastes for about $945 \mathrm{~kg}$ for the next year from initial condition. It indicated that the firts scenario is very optimal because it has fulfilled the need of mineral water for the academicians by providing potable water at Ma Chung University.
\end{abstract}

Keywords:

Dynamic System, System Modeling, Waste Management, Optimal Solution.

\section{Pendahuluan}

Aktivitas manusia dalam memenuhi kebutuhan tidak dapat dihindari dengan menghasilkan sampah. Peningkatan sampah terus terjadi setiap tahunnya, di kota Malang peningkatan sampah per hari mencapai 640 ton. Salah satu elemen yang berdampak pada peningkatan penumpukan sampah di Indonesia, khususnya di kota Malang adalah aktivitas akademik. Universitas Ma Chung merupakan salah satu lembaga pendidikan yang berada di kota Malang. Pemenuhan kebutuhan akademis menjadi upaya Universitas Ma Chung dalam mendukung proses pembelajaran untuk menyediakan fasilitas bagi mahasiswa seperti fasilitas area kantin. Berbagai macam makanan dan minuman dapat diperoleh di kantin tersebut, namun sebagian besar penjual di kantin Universitas Ma Chung menggunakan wadah plastik yang meliputi botol plastik, styrofoam dan tas plastik untuk menunjang penjualan. Bahan plastik ini merupakan bahan yang sulit untuk di uraikan, selain itu terdapat sampah organik (sampah makanan, sayuran, minuman) yang dihasilkan dari kantin serta media kertas yang masih digunakan di Universitas Ma Chung untuk mendukung kegiatan akademik. Namun belum adanya pengelolaan sampah yang baik untuk meminimalkan penggunaan sampah, serta kesadaran terhadap dampak yang diakibatkan oleh sampah di Universitas Ma Chung. Pengelolaan sampah yang sesuai dapat meminimalkan terjadinya penumpukan sampah. Oleh karena itu diperlukan untuk menentukan skenario perbaikan yang sesuai untuk pemilihan kebijakan dalam upaya menjadikan 
Universitas Ma Chung menjadi Eco Campus dengan mengetahui penyebab terjadinya penggunaan sampah yang berlebih menggunakan Sistem Dinamis.

\section{Tinjuan Pustaka}

Penelitian yang dilakukan oleh [3] dengan judul Perancangan Model Simulasi Pengelolaan Sampah Dengan Pendekatan Sistem Dinamis Di Kota Cilegon. Penelitian dilakukan adalah untuk meningkatkan pelayanan kebersihan dengan merancang model simulasi pengelolaan sampah untuk mendapatkan alternatif kebijakan. Kelebihan dari penelitian ini adalah ruang lingkup yang luas. Sedangkan pada penelitian yang akan dilakukan adalah untuk memenuhi kebutuhan sivitas akademik Universitas Ma Chung dengan pembuatan skenario agar sampah yang dihasilkan dapat diminimalkan.

Sistem dinamis membahas interaksi berbagai elemen sistem pada waktunya dan menangkap aspek dinamis dengan memasukkan konsep seperti umpan balik, dengan demikian memberikan wawasan tentang perilaku dinamis sistem dari waktu ke waktu [2]. Pemodelan sistem dinamik dapat memanfaatkan prosedur untuk merumuskan model, berikut merupakan langkah-langkahnya [5]:

1. Causal loop diagram

Digunakan untuk membuat diagram sebab akibat antara untuk menggambarkan hubungan yang terjadi antara variabel-variabel yang ada, tujuannya untuk mengurangi kompleksitas sistem dalam kajian yang sangat penting bagi perilaku keseluruhan sistem.

2. Stock flow diagram

Pada langkah ini stock flow diagram dikembangkan dari causal loop diagram dan divisualisasikan melalui perangkat lunak profesional tujuannya adalah untuk simulasi kuantitatif dan analisis.

3. Dasar menjalankan simulasi

Langkah selanjutnya adalah analisis simulasi bertujuan untuk memahami sistem apa adanya, dengan periode waktu yang telah ditentukan.

4. Analisis skenario

Langkah terakhir ini menawarkan wawasan ke alternatif pengelolaan yang berpotensi akan memperbaiki perilaku sistem saat ini.

Subjektivitas seseorang merupakan faktor penting dalam membangun sebuah model, oleh karena itu diperlukan penyempurnaan yang harus dilakukan secara terus-menerus dengan menggali informasi yang relevan [4]. Sistem dinamis dapat dilakukan dengan Causal Loop Diagram. Causal Loop Diagram biasa disebut diagram sebab akibat, dalam Causal Loop Diagram terdapat dua macam yakni positif feed back loop dan negatif feed back loop. Positif feed back loop merupakan kenaikan satu variabel juga menyebabkan peningkatan pada variabel yang lain, tetapi sebaliknya pengurangan satu variabel menyebabkan pengurangan pada variabel lain. Sebaliknya jika hubungan negatif feed back loop merupakan peningkatan satu variabel akan menyebabkan penurunan untuk variabel lain [1]. Pada pembuatan causal loop diagram dilakukan menggunakan software Vensim. Stock and Flow Diagram juga merupakan konsep utama dari metode sistem dinamis. Tujuannya adalah untuk merepresentasikan struktur dengan teliti untuk dikembangkan dalam formulasi matematis model sehingga dapat disimulasikan. Stock and Flow Diagram dilakukan dengan software Stella.

\section{Metode Penelitian}

Berikut merupakan diagram alir penelitian:

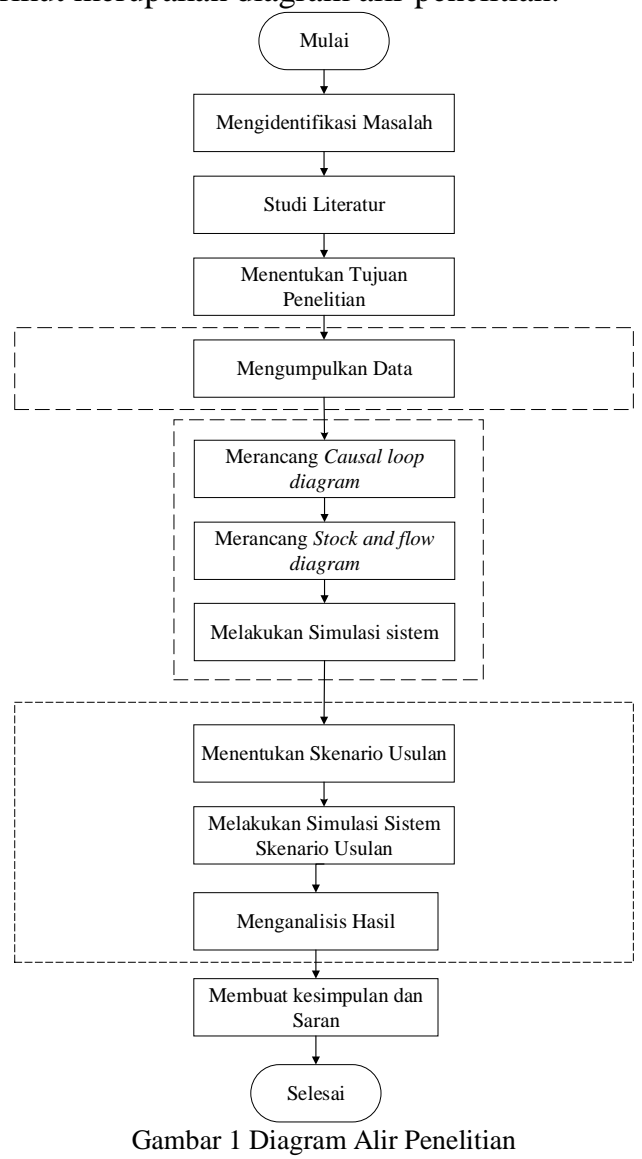

Identifikasi masalah dalam penelitian ini adalah sampah yang dihasilkan dari akademis maupun operasional baik sampah organik (sampah makanan, sayuran, minuman) dan sampah anorganik (kertas, tas plastik, botol plastik, wadah plastik dan styrofoam). Studi literatur didapatkan dari jurnal, buku, dan penelitian terdahulu yang berkaitan dengan sistem dinamis. Tujuan dari penelitian adalah Mengindentifikasi dan melakukan observasi faktor-faktor yang mempengaruhi kebijakan terkait sampah yang ada di universitas 
saat ini, memodelkan sistem dan melakukan simulasi sistem untuk mengevaluasi skenario awal, agar didapatkan alternatif skenario usulan serta menganalisis perbandingan alternatif skenario usulan untuk menentukan skenario paling optimal. Pengumpulan data dilakukan dengan melakukan observasi untuk mengetahui kondisi awal dari pengelolaan sampah di Universitas Ma Chung dan melakukan wawancara kepada pihak-pihak terkait yang mengetahui tentang permasalahan yang ada. Penentuan variabel dilakukan sebelum perancangan causal loop diagram. Variabel yang dipilih merupakan variabel yang mempengaruhi sampah yang dihasilkan di Universitas Ma Chung. Perancangan ini dilakukan untuk mengetahui dengan pasti faktor-faktor apa saja yang menyebabkan dan mengakibatkan sampah di Universitas Ma Chung dihasilkan. Setelah merancang causal loop diagram selanjutnya dilakukan perancangan stock and flow diagram. Stock and flow diagram merupakan pemodelan yang dilakukan dalam sistem dinamis. Variabelvariabel yang sudah terpilih ditentukan nilai dari setiap varibel tersebut untuk dapat dilakukan pemodelan stock and flow diagram. Selanjutnya dilakukan simulasi sistem dengan menjalankan pemodelan yang sudah dibuat. Penentuan skenario usulan didapatkan setelah melakukan analisis terhadap skenario awal yang ada Universitas Ma Chung. Skenario usulan didapatkan berdasarkan observasi yang telah dilakukan, penentuan skenario usulan secara subjektif dari peneliti yang paling memungkinkan untuk dapat diterapkan secara langsung, dilakukan untuk mengurangi atau menghilangkan akibat dari masalah yang ditimbulkan, agar dapat diterapkan di Universitas Ma Chung. Setelah didapatkan skenario usulan, dilakukan simulasi dan menganalisis hasil dan langkah terakhir adalah membuat kesimpulan dan saran.

\section{Hasil dan Pembahasan}

Universitas Ma Chung merupakan salah satu lembaga pendidikan yang berada di Kota Malang, letaknya di Villa Puncak Tidar N-01. Universitas ini resmi dibuka pada tanggal 7 Juli 2007. Lokasi yang jauh dari keramaian dan berada di daratan tinggi dipilih dengan tujuan untuk memberikan suasana yang nyaman bagi mahasiswa. Selain itu terdapat beberapa gedung di dalam universitas guna menunjang proses perkuliahan diantaranya gedung rektorat yang digunakan sebagai tempat penerimaan mahasiswa serta tempat para pengurus universitas, gedung balai pertiwi sebagai tempat olahraga, gedung $\mathrm{RnD}$ sebagai tempat penelitian, gedung bhakti persada sebagai tempat pembelajaran dan gedung student center sebagai tempat makan. Pengelolaan sampah yang ada di Universitas $\mathrm{Ma}$ Chung meliputi pengumpulan, pengangkutan dan pemrosesan akhir. Pengumpulan sampah dilakukan oleh warga universitas dari konsumsi sampah yang dihasilkan. Sedangkan pengangkutan dan pemrosesan akhir dilakukan oleh cleaning service dari sumber sampah sampai pembuangan di container yang ada di dalam universitas. Pembuangan sampah dari gedung ke contaner dilakukan setiap pagi hari yakni pada pukul 10.00 WIB. Gedung Balper, Bhakper, RnD dan Rektorat dilakukan setiap satu kali pembuangan. Sedangkan Gedung SC dilakukan dua kali pembuangan ke container. Pengangkutan sampah ke TPS dilakukan setiap pukul 11.00 WIB dengan gerobak motor oleh petugas kebersihan sekitar wilayah Universitas Ma Chung.

Penelitian yang dilakukan selama 37 hari yakni pada tanggal 19 Maret 2018 s/d 11 Mei 2018. Berdasarkan penelitian yang sudah dilakukan didapatkan jumlah sampah sebesar 260,4 kg selama 37 hari, dengan rata-rata sampah yang dihasilkan $32,87 \mathrm{~kg}$ per hari. Berikut merupakan grafik yang di tunjukkan dalam pie chart:

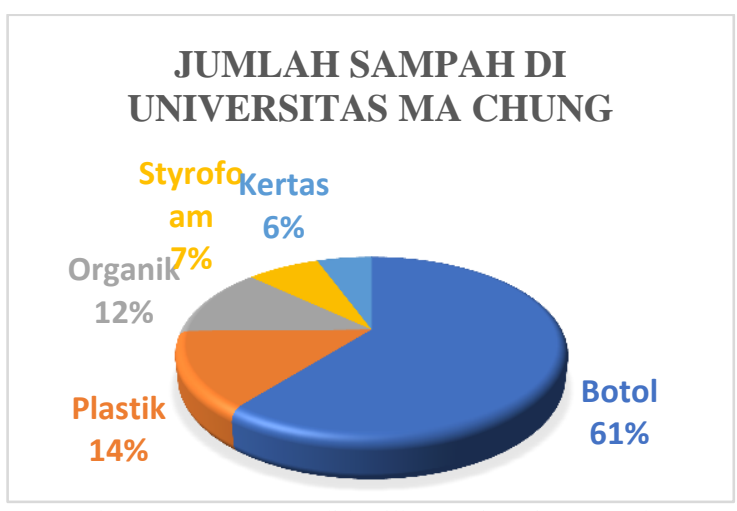

Gambar 2 Sampah yang di hasilkan Universitas Ma Chung

Pada grafik menunjukkan bahwa jumlah sampah botol sangat dominan, jumlah sampah yang dihasilkan di Universitas Ma Chung sebesar $158 \mathrm{~kg}$ selama 37 hari penelitian, sehingga rata-rata per hari sampah botol yang dihasilkan sebesar $4,27 \mathrm{~kg}$ per hari. Jumlah sampah plastik sebesar $36,6 \mathrm{~kg}$ selama 37 hari, rata-rata sampah plastik yang dihasilkan sebesar 989,19 gram per hari, jumlah sampah organik sebesar $32 \mathrm{~kg}$ selama 37 hari, ratarata sampah organik yang dihasilkan sebesar 864,86 gram per hari, jumlah sampah styrofoam sebesar $19,3 \mathrm{~kg}$ selama 37 hari, rata-rata sampah styrofoam sebesar 521,62 gram per hari dan jumlah sampah kertas sebesar $14,5 \mathrm{~kg}$ selama 37 hari, rata-rata sampah kertas sebesar 391,89 gram per hari.

Setelah melihat kondisi awal Universitas Ma Chung selanjutnya ditentukan identifikasi variabel, yang merupakan tahap awal dalam sistem dinamis. Terdapat 20 variabel yang sudah ditentukan sesuai dengan kondisi awal. Variabel-variabel tersebut antara lain rata-rata sampah organik di bhakper, rata-rata sampah organik di balper, rata-rata sampah organik di SC, rata-rata sampah organik di $\mathrm{RnD}$, rata-rata sampah organik di rektorat, jumlah 
sampah anorganik di bhakper, jumlah sampah anorganik di balper, jumlah sampah anorganik di $\mathrm{SC}$, jumlah sampah anorganik di $\mathrm{RnD}$, jumlah sampah anorganik di rektorat, jumlah sampah di bhakper, jumlah sampah di balper, jumlah sampah di SC, jumlah sampah di RnD, jumlah sampah di rektorat, jumlah sampah organik di UMC, jumlah sampah anorganik di UMC, jumlah sampah yang terangkut ke TPS dan dampak potensi jejak karbon. Berdasarkan identifikasi variabel tersebut dilakukan pembuatan causal looop diagram seperti berikut:

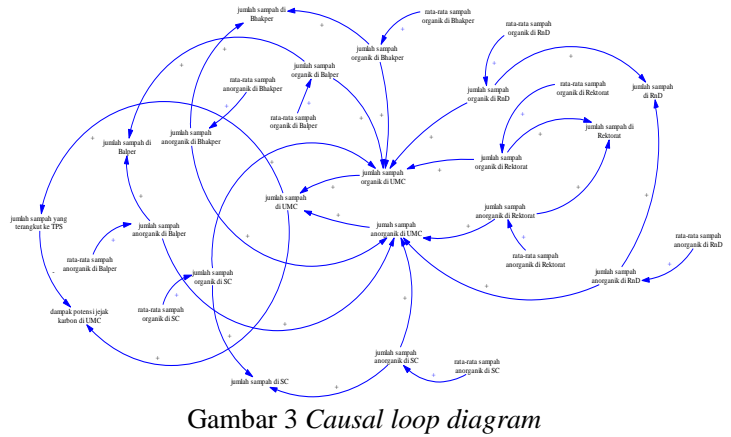

Langkah ketiga adalah membuat stock and flow diagram dari masing-masing variabel. Berikut merupakan stock and flow diagram dari jumlah sampah anorganik yang ada di Universitas Ma Chung.

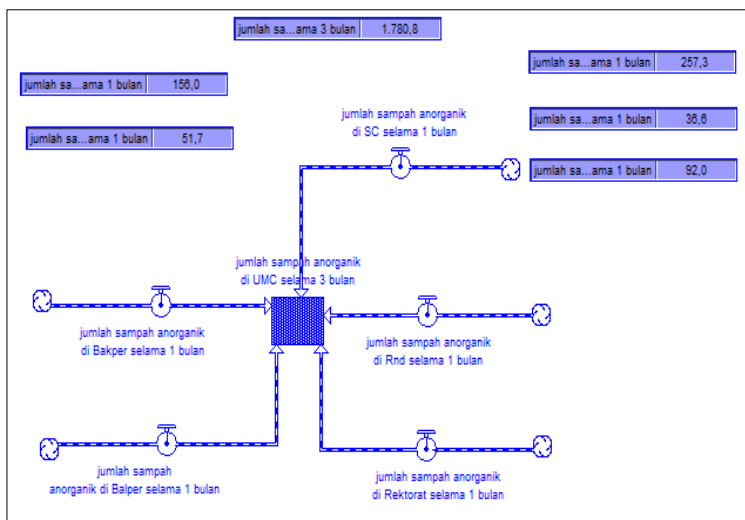

Gambar 4 Stock and Flow Diagram Jumlah Sampah Anorganik di Universitas Ma Chung

Bentuk persegi adalah stok dari sampah anorganik yang ada di Universitas Ma Chung. Inflow yang masuk ke dalam stok adalah jumlah sampah anorganik dari masing-masing gedung selama 1 bulan dari hasil simulasi. Bhakper $156 \mathrm{~kg} / \mathrm{bulan}$, Balper 92 kg/bulan, SC 257,3 kg/bulan, RnD 51,7 $\mathrm{kg} /$ bulan dan Rektorat 36,6 kg/bulan. Peningkatan jumlah sampah anorganik yang ada di UMC selama 3 bulan ke depan didapatkan sebesar $1.780,8 \mathrm{~kg} / 3$ bulan. Berikut merupakan grafik dari jumlah sampah anorganik yang ada di Universitas Ma Chung.

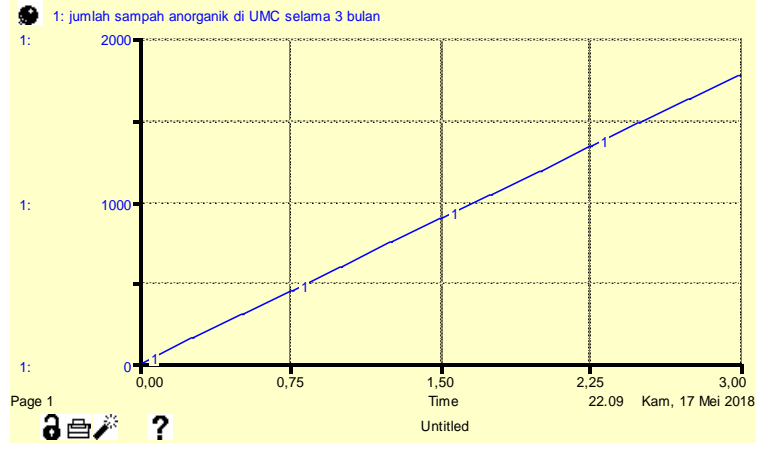

Gambar Grafik Jumlah Sampah Anorganik di UMC

Selain jumlah sampah anorganik, didapatkan juga jumlah sampah organik di Universitas Ma Chung.

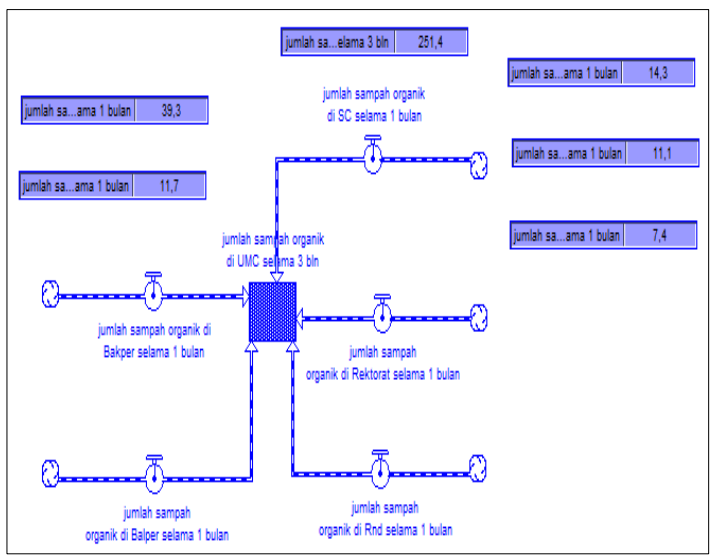

Gambar 5 Stock and Flow Diagram Jumlah Sampah Anorganik di Universitas Ma Chung

Bentuk persegi adalah stok dari sampah organik yang ada di Universitas Ma Chung. Inflow yang masuk ke dalam stok adalah jumlah sampah organik dari masing-masing gedung selama 1 bulan dari hasil simulasi. Bhakper 14,3 kg/bulan, Balper $11,7 \mathrm{~kg} / \mathrm{bulan}, \quad \mathrm{SC} 39,3 \mathrm{~kg} / \mathrm{bulan}, \mathrm{RnD} 11,1$ $\mathrm{kg} /$ bulan dan Rektorat 7,4 kg/bulan. Peningkatan jumlah sampah organik yang ada di UMC selama 3 bulan ke depan didapatkan sebesar $251,4 \mathrm{~kg} / 3$ bulan. Berikut merupakan grafik dari jumlah sampah organik yang ada di Universitas Ma Chung.

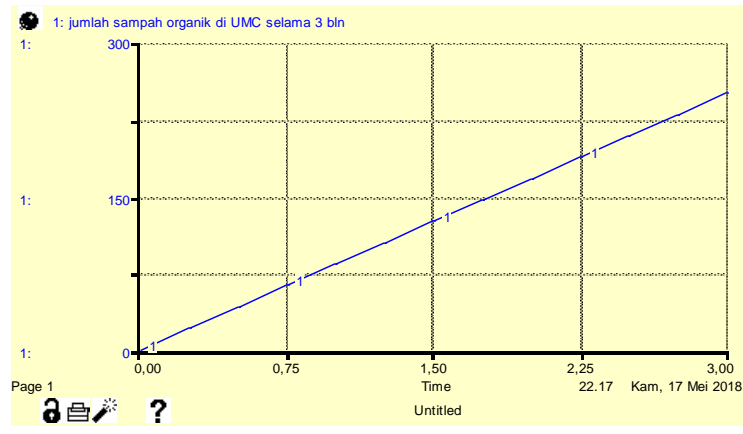

Gambar 6 Grafik Jumlah Sampah Organik di UMC 
Setelah didapatkan stock and flow diagram jumlah sampah anorganik dan jumlah sampah organik di Universitas Ma Chung, berikut merupakan stock and flow diagram jumlah sampah yang terangkut ke TPS:

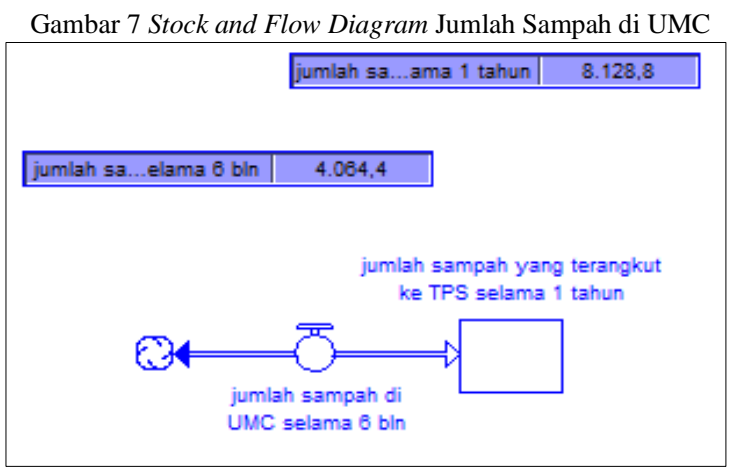

Bentuk persegi adalah stok dari jumlah sampah yang terangkut ke TPS. Inflow yang masuk ke dalam stok adalah jumlah sampah di Universitas Ma Chung selama 6 bulan berdasarkan hasil simulasi. Jumlah sampah di Universitas Ma Chung sebesar 4.064,4 kg/ 6 bulan. Peningkatan jumlah sampah yang terangkut ke TPS selama 1 tahun ke depan didapatkan sebesar 8.128,8 kg/tahun. Berikut merupakan grafik dari jumlah sampah yang terangkut ke TPS.

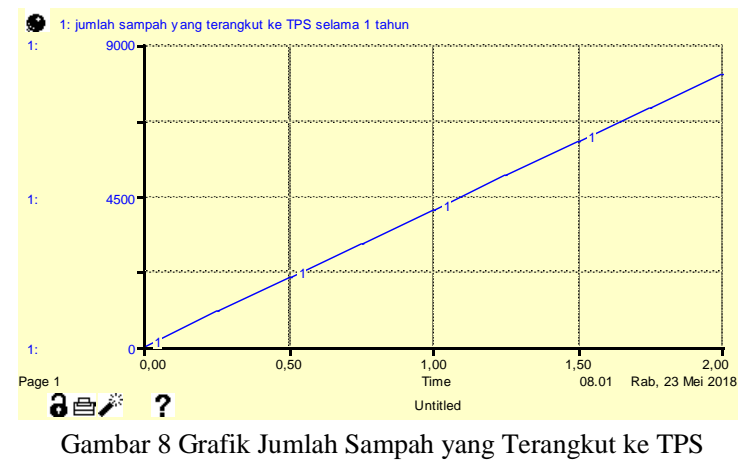

Penentuan skenario ditentukan berdasarkan kondisi yang ada pada saat ini, dengan menyebarkan kuesioner mengenai usulan-usulan yang akan dilakukan kepada sivitas akademik Universitas Ma Chung (jumlah staff dan dosen tahun 2018, serta jumlah mahasiswa angkatan 2014-2017). Jumlah mahasiswa sebesar 1.042 dan jumlah staff dan dosen sebesar 163 orang. Pada kuesioner terdapat dua pertanyaan alternatif skenario usulan mengenai pengelolaan sampah di Universitas Ma Chung. Usulan pertama dengan mengusulkan adanya air siap minum di universitas tujuannya adalah untuk mengurangi peredaran sampah botol plastik yang saat ini merupakan penyumbang sampah paling besar dari universitas dan usulan kedua yakni dengan mengusulkan membawa tempat makan sendiri untuk membungkus makanan yang tidak di makan di kantin, tujuannya untuk mengurangi penggunaan styrofoam di universitas.

Berdasarkan hasil kuesioner sebanyak 143 orang mengisi dengan perolehan sebesar 92,2\% memilih pada skenario usulan pertama, sisanya $7,8 \%$ tidak memilih. Pada skenario usulan kedua $70 \%$ responden memilih iya dan $30 \%$ tidak memilih.

Perhitungan menggunakan stock and flow diagram juga dilakukan pada kedua skenario usulan. Simulasi sistem dilakukan untuk skenario usulan pertama yakni pada pengurangan penggunaan botol plastik, dengan menjalankan stock and flow jumlah sampah yang ada di Universitas Ma Chung selama 6 bulan menggunakan software Stella. Berikut merupakan

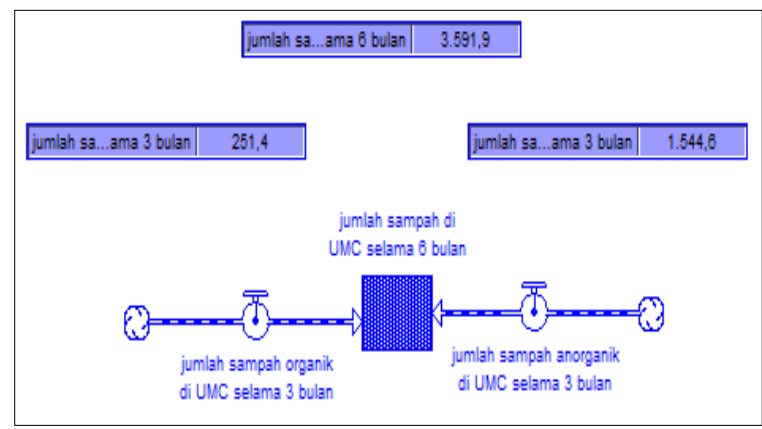

gambar simulasi:

\section{Gambar 9 Stock and Flow Diagram Jumlah Sampah di} UMC Usulan Pertama Selama 6 Bulan

Inflow yang masuk ke dalam stok adalah jumlah sampah organik dan anorganik selama 3 bulan berdasarkan hasil simulasi. Sampah organik di Universitas Ma Chung sebesar 251,4 kg/ 3 bulan sedangkan jumlah sampah anorganik di Universitas Ma Chung sebesar $1.780,8 \mathrm{~kg} / 3$ bulan dikurangi dengan 236,23 kg/ 3 bulan. Pada sampah anorganik dilakukan pengurangan dikarenakan 92,2\% responden memilih untuk menerima usulan, sehingga jumlah sampah anorganik akan berkurang. Peningkatan jumlah sampah yang ada di UMC selama 6 bulan ke depan didapatkan sebesar $3.591,9 \mathrm{~kg} / 6$ bulan.

Gambar 10 Grafik Jumlah Sampah di UMC Usulan Pertama Selama 6 Bulan

Gambar 11 Stock and Flow Diagram Jumlah Sampah Usulan

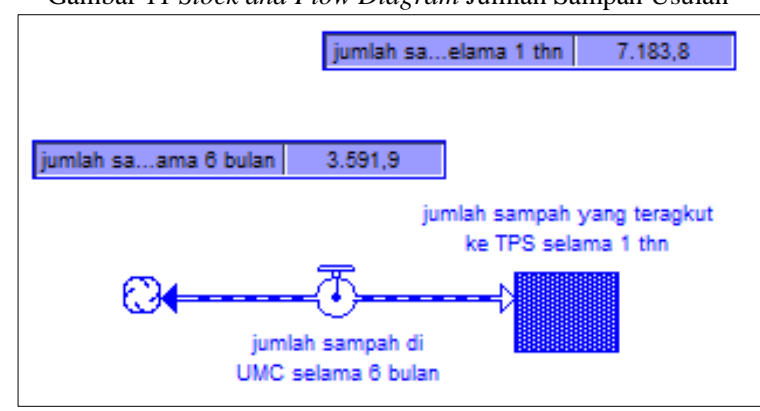

Pertama yang Terangkut ke TPS 


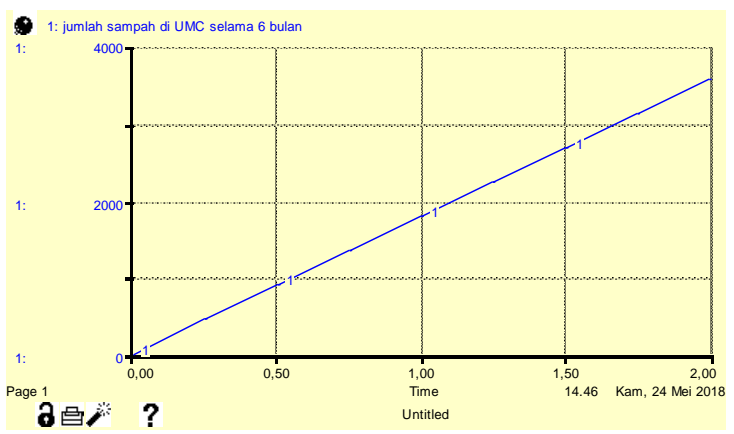

Inflow yang masuk ke dalam stok adalah jumlah sampah di Universitas Ma Chung selama 6 bulan berdasarkan hasil simulasi. Jumlah sampah di Universitas Ma Chung sebesar 3.591,9 kg/ 6 bulan. Peningkatan jumlah sampah yang terangkut ke TPS selama 1 tahun ke depan didapatkan sebesar $7.183,8 \mathrm{~kg} / \mathrm{tahun}$.

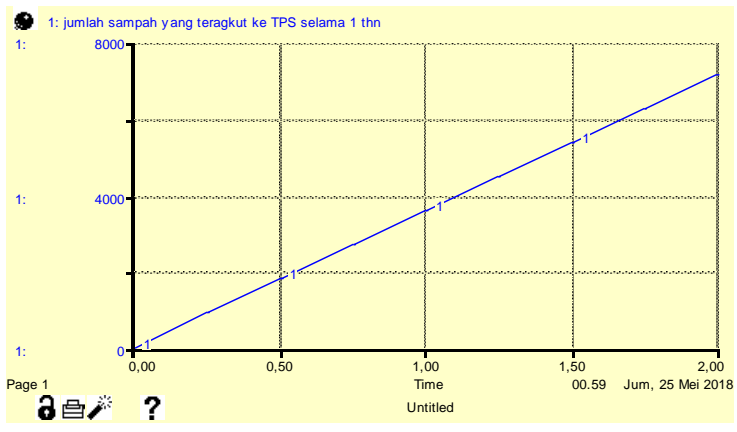

Gambar 12 Grafik Jumlah Sampah Usulan Pertama yang Terangkut ke TPS

Simulasi sistem juga dilakukan untuk skenario usulan kedua yakni pada pengurangan penggunaan styrofoam, dengan menjalankan stock and flow jumlah sampah yang ada di Universitas Ma Chung selama 6 bulan menggunakan software Stella. Berikut merupakan gambar simulasi:

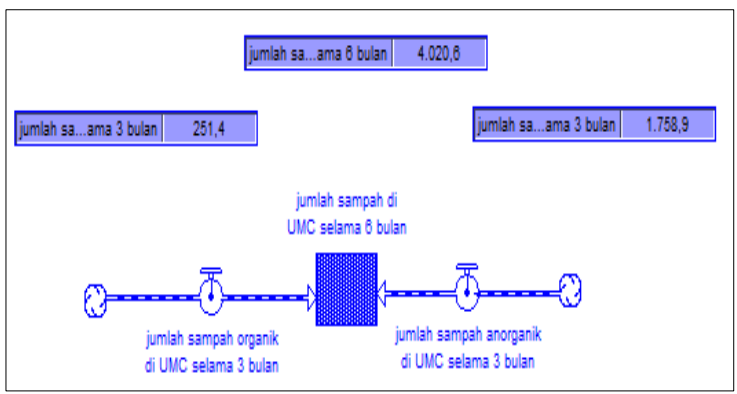

Gambar 13 Stock and Flow Diagram Jumlah Sampah di UMC Usulan Kedua Selama 6 Bulan

Inflow yang masuk ke dalam stok adalah jumlah sampah organik dan anorganik selama 3 bulan berdasarkan hasil simulasi. Sampah organik di Universitas Ma Chung sebesar 251,4 kg/ 3 bulan sedangkan jumlah sampah anorganik di Universitas Ma Chung sebesar $1.780,8 \mathrm{~kg} / 3$ bulan dikurangi dengan 21,908 kg/ 3 bulan. Pada sampah anorganik dilakukan pengurangan dikarenakan $70 \%$ responden memilih untuk menerima usulan, sehingga jumlah sampah anorganik akan berkurang. Peningkatan jumlah sampah yang ada di UMC selama 6 bulan ke depan didapatkan sebesar $4.020,6 \mathrm{~kg} / 6$ bulan.

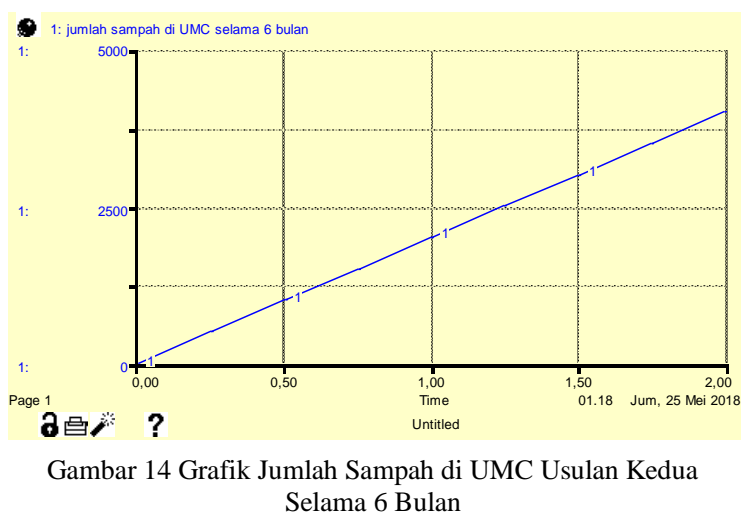

Gambar 15 Stock and Flow Diagram Jumlah Sampah Usulan

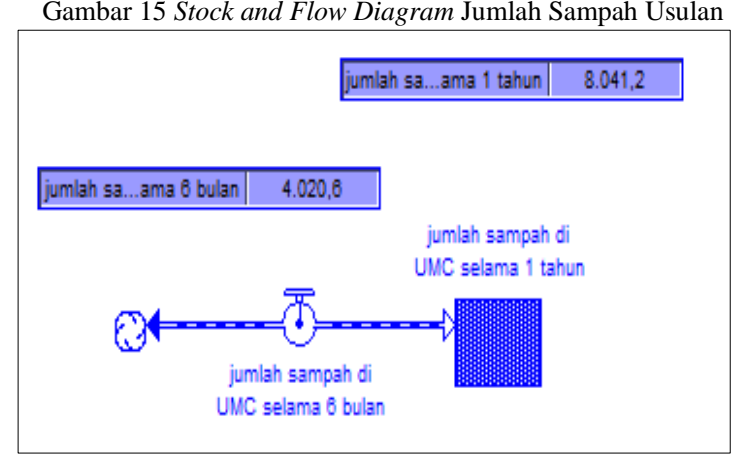

Kedua yang Terangkut ke TPS

Inflow yang masuk ke dalam stok adalah jumlah sampah di Universitas Ma Chung selama 6 bulan berdasarkan hasil simulasi. Jumlah sampah di Universitas Ma Chung sebesar 4.020,6 kg/ 6 bulan. Peningkatan jumlah sampah yang terangkut ke TPS selama 1 tahun ke depan didapatkan sebesar $8.041,2 \mathrm{~kg} /$ tahun.

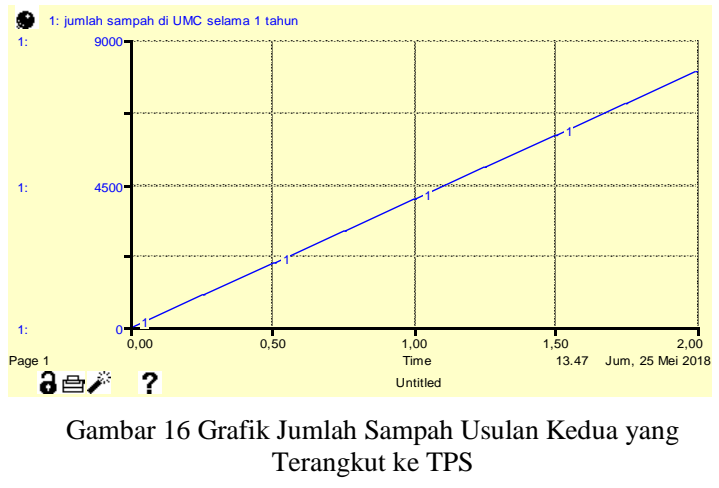


Berdasarkan simulasi yang telah dilakukan pada skenario awal, skenario usulan pertama dan skenario usulan kedua dapat diketahui bahwa jumlah sampah yang dihasilkan di Universitas Ma Chung pada skenario usulan pertama lebih rendah dan dapat mencukupi kebutuhan sivitas akademik. Perbandingan nilai skenario awal dan skenario usulan pada simulasi sebesar $945 \mathrm{~kg} /$ tahun, sedangkan perbandingan nilai pada skenario awal dan skenario usulan kedua sebesar 87,6 kg/tahun.

\section{Kesimpulan dan Saran}

Penelitian yang dilakukan adalah analisis dan pemodelan sistem pengelolaan sampah yang ada di Universitas Ma Chung, dengan observasi yang dilakukan selama 37 hari untuk mengetahui kondisi awal yang akan dijadikan skenario awal. Kemudian dilanjutkan dengan menentukan variabel-variabel, membuat causal loop diagram dan membuat stock and flow diagram. Berdasarkan identifikasi variabel didapatkan 20 variabel. Pada perhitungan stock and flow diagram nilai skenario awal didapatkan dari simulasi, untuk jumlah sampah di UMC selama 1 tahun ke depan sebesar 8.128,8 kg/tahun. Kemudian ditentukan dua usulan yang paling memungkinkan untuk dapat diterapkan tujuannya adalah untuk mengurangi sampah yang dihasilkan di Universitas Ma Chung. Hal ini didukung dengan kemauan sivitas akademik untuk menerima usulan yang diberikan menggunakan kuesioner. Usulan pertama adalah menyediakan air siap minum di universitas dan usulan kedua adalah membawa tempat makan sendiri untuk membungkus makanan. Berdasarkan hasil kuesioner tersebut 92,2\% menerima usulan pertama dan $70 \%$ menerima usulan kedua.

Skenario usulan pertama dan skenario usulan kedua dilakukan perhitungan sama dengan skenario awal, dan didapatkan hasil simulasi untuk jumlah sampah selama satu tahun ke depan pada skenario usulan pertama sebesar 7.183,8 kg/tahun dan jumlah sampah selama satu tahun ke depan pada skenario usulan kedua sebesar 8.041,2 $\mathrm{kg} /$ tahun.

Berdasarkan hal tersebut, skenario usulan pertama merupakan usulan yang paling optimal, untuk tercukupinya kebutuhan konsumsi makanan dan minuman serta barang yang dibutuhkan sivitas akademik. Sehingga penurunan skenario awal dan skenario mengenai adanya air siap minum sebesar $945 \mathrm{~kg}$ sampah per tahun.

\section{Daftar Pustaka}

[1] Dangerfield, B. (2014). System Thinking and System Dynamics: A Primer. University of Bristol.

[2] Tang, V. dan Vijay, S. (2001). System Dynamics: Origins, Development and Future Prospects of a Method. Research Semina in Engineering Systems.
[3] Wildanurrizal, Bhauddin. A, Ferdinant. P.F (2012). Perancangan Model Simulasi Pengelolaan Sampah Dengan Pendekatan Sistem Dinamis Di Kota Cilegon. Jurnal Teknik Industri, Universitas Sultan Ageng Tirtayasa. Banten.

[4] Winardi. (1989). Pengantar Tentang Teori Sistem dan Analisis Sistem. Mandar Maju, Bandung.

[5] Yuan, H. (2012). A Model for Evaluating the Social Performance of Construction Waste Management. Waste Management 32, 1218-1228. 